\title{
Arte outsider - transformando a margem em centro
}

\author{
Vera L. Zolberg'
}

\section{Introdução}

Para a maioria das pessoas, a arte outsider, também chamada de arte "bruta" ou "marginal" - gênero associado aos "loucos" confinados em hospitais psiquiátricos - era uma curiosidade indigna de ser levada a sério. Este ponto de vista deriva muito de como os próprios loucos eram vistos. Distanciados dos encontros humanos comuns, seja por inépcia social ou falta de vontade de se comportar de forma socialmente aceitável, alguns foram encorajados a desenhar e pintar como forma de terapia experimental, a partir do início do século XX. Nos últimos anos, alguns de seus trabalhos foram elevados a novos patamares de significância, reavaliados e transformados em itens de colecionador. Além disso, o gênero ampliou-se e passou a englobar as criações de outros outsiders, isto é, outros "outros". Aos portadores de doenças mentais internados, está sendo acrescentado um novo elenco de personagens - artistas populares de áreas rurais isoladas; moradores de rua em abrigos; detentos; idosos em casas de repouso; pacientes terminais. Qualificados de diversas formas - ingênuos², visionários compulsivos ou simplesmente outsiders -, seu reconhecimento levou, no fim do século XX, a uma nova reflexão sobre o posicionamento da arte e dos artistas em relação a outras esferas sociais.

Os outsiders não se encaixam, de forma alguma, em categorias mutuamente exclusivas ou estáticas. No decorrer de suas vidas, estes indivíduos são internados e recebem alta; habitam periferias e áreas urbanas mais ou menos isoladas; além de representar diversas faixas etárias, níveis educacionais, etnias, raças e, até certo ponto, classes sociais. 
Artistas heterogêneos e maleáveis, eles compartilham uma alegada falta de treinamento artístico formal e a ideia de que seus trabalhos não são arte. De fato, considera-se que estes outsiders não devam se autodefinir como artistas, seja inicialmente ou mesmo após serem assim caracterizados por outros. Quando seus trabalhos são apresentados como arte, a iniciativa parece partir de marchands, galerias, críticos, acadêmicos, museus e artistas profissionais, ao invés dos próprios artistas (DUBIN, 1997).

É importante manter estes fatos em mente quando se nota que, no decorrer dos últimos anos, as obras dos outsiders têm sido alçadas a níveis surpreendentes de valor monetário e estatura simbólica. As galerias e os marchands especializados, que apareceram nos Estados Unidos e Europa, demonstram uma sede insaciável por objetos deste tipo para expor e vender. Sua avidez levou-os a organizar expedições de prospecção virtual para atender à crescente demanda de grandes grupos de colecionadores em busca de obras a preços razoáveis. No dia a dia do mercado de arte, a presença dos outsiders nas mostras internacionais tem se tornado cada vez mais comum e frequente. Nas revistas especializadas em arte, os textos atiçam os colecionadores: críticas, exaltações redigidas pelos promotores da arte outsider, registros de descobertas intrigantes, bem como explanações da importância deste novo nicho. ${ }^{3}$ Até mesmo museus tornaram-se anfitriões destes trabalhos, promovendo exposições temporárias de arte outsider ou mesmo legitimando-a por completo, adicionando estas obras a seus acervos permanentes.

Neste contexto, ficou evidente a significância da quarta edição anual da Outsider Art Fair, realizada no Edifício Puck em Nova York no inverno de 1996. Multidões de visitantes mostraram-se dispostas a pagar 10 dólares para ver as últimas descobertas nesta seara. Com o mesmo fervor, procuraram os "clássicos", uma missão na qual não se desapontaram. Havia várias obras sendo vendidas por preços bastante respeitáveis: desenhos em papel de Adolf Wölfli, o primeiro paciente psiquiátrico internado (na Suíça) a ser "descoberto", datados de 1922, à venda por 40.000 dólares; e desenhos datados de 1950 por Martin Ramirez, paciente psiquiátrico mexicano que passou os últimos anos de sua vida confinado em um hospital psiquiátrico na Califórnia, sendo vendidos por 35.000 dólares. Estes não foram, de 
maneira alguma, os maiores valores já pagos por tais obras (BOWLER, 1977). Se alguém duvidava que a arte outsider pudesse emigrar de uma existência obscura, externa às fronteiras da arte tradicional, estes eventos recentes demonstram que ela já ganhou sua cidadania (ou, pelo menos, valor monetário), sinal de sua naturalização no mundo da arte. É possível notar claramente que, junto à "tradição do novo", conforme caracterizado tão acertadamente por Harold Rosenberg quanto ao sucesso da arte moderna, hoje a arte outsider já é uma tradição vibrante (ROSENBERG, 1965).

Oflerte com a arte outsider e o sucesso financeiro que ela proporcionou aos seus marchands e colecionadores pode ter sido uma surpresa para os simpatizantes da arte não tradicional e seus artistas. No entanto, a revalorização da arte antiacadêmica, que tem ocorrido desde o último terço do século XIX, deveria tê-los preparado para estes desdobramentos. Independentemente de outros motivos, alguns colecionadores apostaram na possibilidade de que a história pudesse se repetir e que seus investimentos relativamente baixos pudessem eventualmente gerar retornos altíssimos. De fato, ao se incorporar a criatividade dos outsiders como candidata a adentrar o centro do domínio estético, traça-se um paralelo com a história da inovação artística ao longo do século XIX e início do XX. Ao observar este paralelo, não estou alegando que o crescimento da arte outsider seja equivalente à adição do Impressionismo ou Pós-Impressionismo ao cânone, ${ }^{4}$ uma vez que as condições atuais diferem significativamente daquelas existentes no que hoje se considera ter sido a era clássica da história da arte moderna.

\section{A natureza da mudança da estética}

Entende-se que o processo de mudança da arte, seja na forma ou no conteúdo, provém geralmente de uma de duas coisas: um desenvolvimento do paradigma corrente; ou como resultado de novas ideias importadas de fora das estruturas estéticas convencionais (CLIGNET, 1985; KUHN, 1970; BECKER, 1982; CRANE, 1987). Seja qual for o caso, tal inovação geralmente representa um processo proposital desempenhado por profissionais

\footnotetext{
O termo "Pós-Impressionismo" é geralmente atribuído a Roger Fry, crítico inglês que assim caracterizou as obras que selecionou para duas importantes exposições na Grafton Gallery de Londres, em 1910-1911 e em 1912. Dentre o pot-pourri de estilos lá representados destacaramse $\circ$ Neoimpressionismo, o Cloisonismo, ○ Cubismo e o Fauvismo. Para uma descrição destes eventos de grande importância artística, veja Les grandes collections privées de Douglas Cooper (Paris: Editions du Pont Royal, 1963).
} 
conscientes das regras que estão violando. Isto é verdade mesmo no caso dos artistas dissidentes que compõem os grupos de vanguarda que tentam sobrepujar "o cânone" (BECKER, 1982). Também é comum que grupos ostracizados, como mulheres, minorias raciais ou étnicas, busquem penetrar o centro do mundo artístico corrente, desafiando ou não sua estética formal prevalente.

A margem, de onde emana a arte outsider, é uma fonte importante de mudança estética, tanto ao gerar conceitos estéticos contestatórios (CHERBO, ROGOFF, SUSSMANN, EM ZOLBERG E CHERBO, 1997), quanto ao incluir grupos sub-representados (FINNEY, ROGOFF, SZANTO, SUSSMANN, ZOLBERG, EM ZOLBERG E CHERBO, 1997). Além destas fontes de inovação, eu gostaria de argumentar que a mudança estética pode, igualmente, advir de fontes completamente alheias ao domínio estético; pode ser intencional ou não, produzida por profissionais ou não profissionais. Na verdade, a própria natureza da arte do final do século XX implica um processo constante de absorção, apropriação, amalgamação de formas novas e não habituais, bem como a incorporação de um conjunto de pessoas em constante mutação. Para permitir a apreensão deste fenômeno, primeiramente faço considerações sobre o núcleo ou as linhas prevalentes da arte "normal", como ela se constituiu e quais foram as consequências quanto às possibilidades de inclusão ou exclusão.

\section{Como a arte se torna "normal"}

Apesar de sua expansão, o desenvolvimento de estudos acadêmicos sobre arte outsider continua sendo dificultado por barreiras disciplinares e institucionais que desestimulam a comunicação interdisciplinar, mesmo entre áreas muito próximas. Tendo em vista o crescimento do interesse neste assunto, os escritores que se propõem a preencher a lacuna existente na literatura podem não convencer. Conforme observado por Tuchman, por exemplo, "no contexto da história da arte, a atenção dispensada às obras dos outsiders tem sido inadequada" (TUCHMAN E ELIEL, 1992). Esta afirmação é válida na medida em que, dentre o grande número de 
publicações citadas por Tuchman e Eliel em sua catalogação da exposição Parallel Visions, a maior parte foi escrita do ponto de vista de disciplinas que não são aquelas tipicamente associadas à arte: os psicólogos, psiquiatras e antropólogos são mais numerosos do que os críticos, artistas e historiadores de arte. Este primeiro grupo está mais interessado em discutir questões importantes sobre a criatividade como processo humano, as conexões entre o normal e o anormal, o universal e o particular, do que em analisar os critérios para que algo seja considerado arte ou artístico.

No outro extremo da academia estão os teóricos sociais e os críticos teóricos, que rechaçam o indivíduo criador e preferem tratar a grande transformação histórica sob a ótica de uma ideia maior de pós-modernismo. Esta separação entre humanistas e cientistas sociais nos desafia a analisar o contexto a partir de um ponto de vista sociológico que englobe tanto o micromundo do indivíduo - a vida do artista - quanto o macromundo das revoluções sociais e culturais.

Causa surpresa também o fato de que muitos daqueles que participaram do fenômeno de reconhecimento da arte outsider estejam tão fortemente envolvidos na construção deste domínio que aparentam terem se tornado incapazes de afastarem-se da posição de insiders do mundo da arte contemporânea "normal" ou mainstream. ${ }^{5}$ Uma boa parte de seu envolvimento está relacionada ao mercado artístico e à comercialização da arte. Sendo assim, faz-se necessário transcender a gama relativamente estreita de questões orientadas por este envolvimento, buscando uma consideração sobre os fatores que omitem as formas criativas menos suscetíveis a serem tratadas como bens de consumo: formas de dança, apresentações teatrais em ambientes inusitados, obras incomuns expostas ao ar livre, sejam elas permanentes ou efêmeras. Assim, pode-se evitar o que tem sido uma atenção exclusiva, por parte dos analistas, às obras que são portáteis e, portanto, aptas a serem expostas, compradas e vendidas. Ao invés disso, é importante proporcionar ferramentas de análise que transcendam os significados convencionais da arte, assim como a própria arte tem feito.

Ainda assim, é claramente impossível incluir toda a gama imaginável de expressões criativas cujos defensores têm procurado incorporar ao

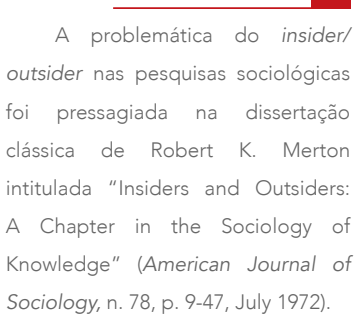


domínio das artes, tais como a tatuagem e, na esfera musical, o rock e o rap. ${ }^{6}$ Em um primeiro momento, nenhuma destas expressões foi criada nem havia qualquer aspiração neste sentido por parte de seus criadores - tendo em vista a inclusão no mundo dos museus ou das orquestras sinfônicas e casas de ópera; porém, a exitosa admissão das obras de videoarte pelas instituições legitimadoras que são os museus de arte nos relembra que estas formas cruzam as fronteiras que delimitam os gêneros das artes visuais e performáticas. Estas expressões artísticas confrontam as instituições que oferecem local propício a uma maior inventividade, abarcando gêneros nunca antes imaginados e incluindo-os em seu universo de referências. É igualmente importante lembrar que, em grande parte, as próprias instituições buscam avidamente abrir-se a uma gama mais ampla de visitantes e clientes, muitos dos quais não são atraídos pelas formas de arte convencionais.

$\mathrm{Na}$ França, historicamente, o reconhecimento ministerial tem sido essencial para a aceitação das novas formas de arte, e foi lá que, nos últimos anos, tem acontecido a mais surpreendente transformação dos posicionamentos em relação à cultura. Embora o governo francês do século XIX, seja por meio de seus ministérios ou suas estruturas acadêmicas, tenha sido extremamente seletivo, opondo-se às inovações nos estilos e formas de arte, a atitude oposta tornou-se prevalente nas últimas duas décadas. Filmes, histórias em quadrinhos, música e jazz dissonante, todos já foram reconhecidos pelo Ministério da Cultura francês como gêneros de importância nacional, coisa que seria inimaginável há algumas décadas.

Com a consequente fertilização cruzada entre as formas de arte, tornase importante examinar alguns dos gêneros estéticos marginalizados que têm ganhado crescente visibilidade nos meios artísticos contemporâneos. O histórico social da mudança artística tida como convencionalmente aceito tem focado primariamente as mudanças na configuração das fontes de patrocínio, quase que exclusivamente na Europa. Incluem-se entre estas as alterações nas estruturas de apoio das cidades-estado da era clássica, das cortes imperiais, da lgreja, dos estados leigos e de aristocratas ou magnatas individuais. Dentre estes, a instituição mais surpreendente e mais estudada é o sistema acadêmico da França, dominado por academias 
oficiais ou semioficiais de pintura ou escultura, ou por conservatórios nacionais de música e artes cênicas. Estas instituições vibrantes e bemsucedidas em promover a profissionalização das profissões estéticas, bem como em recrutar e educar neófitos promissores fomentaram a criatividade e contribuíram para a glória do país. Não é de se espantar, portanto, que variantes deste sistema tenham surgido na maioria dos países europeus. Estas instituições oficiais tornaram-se autoridades na criação dos "estilos" que vieram a simbolizar seus respectivos países e governantes. Entretanto, no processo de criação de uma estrutura de honra de status e potencial econômico, elas também excluíram muitas formas culturais e seus criadores. Por serem "marginais", estes últimos foram incapazes de reivindicar para si a glória que foi, cada vez mais, arrogada ao centro.?

Controladas por artistas bem conectados politicamente, que consolidaram sua autoridade ao supervisionar o sistema de recompensas que constituíam o reconhecimento oficial, fosse ele simbólico ou material, pela criatividade artística a serviço do príncipe (ou do estado, ou da república, conforme o caso), as instituições oficiais garantiram a sucessão de suas ideias por meio da cooptação de novas gerações de artistas. ${ }^{8}$ Recriado após a Grande Revolução e modificado diversas vezes, o sistema acadêmico vicejou durante a maior parte do século XIX. Eventualmente, no entanto, perceberam-se nele uma crescente fossilização estilística e um apreço pela própria autoridade, de tal monta que levava, cada vez mais, à autocooptação. Isto não quer dizer que, necessariamente, todos os seus membros tenham sido burocratas sem talento, como teriam alegado seus críticos e alguns aspirantes frustrados. Tampouco foram tão engessados quanto teriam acusado alguns. As sucessivas mudanças de estilo que dominaram a academia francesa comprovam que, apesar de certa resistência, mesmo a arte Acadêmica passou por mudanças significativas ao longo do século. Porém, conforme argumentado por Harrison e Cynthia White, frente à enxurrada de candidatos desejosos de acesso ao conforto financeiro e ao prestígio personificados pela academia, esta viu-se obrigada a introduzir mecanismos seletivos cada vez mais rigorosos, para controlar o crescimento institucional. ${ }^{9}$

Rejeitados pela academia e por sua instituição oficial de vendas, o Salão de Paris, artistas aspirantes buscaram e contribuíram para a construção 
de novas fontes de apoio dentre os novos patronos burgueses e o crescente mercado de comercialização de arte. Eventualmente, mesmo que apenas raramente no início, muitas de suas inovações estéticas se tornaram mais valorizadas do que a arte de seus contemporâneos "oficiais". A sucessão aparentemente ininterrupta de novos estilos tornou-se uma atividade aceita no meio artístico contemporâneo, com cada nova forma que surgia buscando o reconhecimento oficial e do público. Definindo-se como alheios ao cânone da academia, estes refusés são geralmente apresentados não apenas como inovadores estilísticos, mas também como heróis. Courbet, com seu Naturalismo; os pintores da escola de Barbizon, com sua valorização da paisagem, que antes recebera pouco prestígio na hierarquia Acadêmica dos gêneros artísticos; os Impressionistas e sua relação direta com a natureza; os Neoimpressionistas com suas experimentações científicas; Van Gogh e suas distorções Expressionistas; Gauguin e seu exotismo erótico; Cézanne e suas obras de difícil caracterização ${ }^{10}$; todos tinham em comum o repúdio aos limites impostos pela academia. Ainda assim, na maioria dos casos, eles continuaram a trabalhar dentro dos mesmos formatos, isto é, pintura a óleo em tela, escultura e materiais associados. Por mais que tenham inovado, raramente chegaram a criar gêneros inteiramente novos.

Cada vez mais, os principais agentes dos novos estilos e práticas artísticas tornaram-se criadores treinados no âmbito do mesmo sistema institucional acadêmico que os havia rejeitado. Além da falta de capacidade disponível para educar um grande número de pessoas, e também por medo de inundar uma profissão já superpovoada, os administradores e artistas que dominaram a academia não desejavam compartilhar seus parcos recursos com aqueles cuja inventividade ameaçava suas próprias habilidades e conhecimentos - em cuja aquisição haviam investido pesadamente.

Por outro ponto de vista, o de instituição burocrática, os valores fundamentais da academia entravam em conflito com o conceito cada vez mais prevalente do artista como gênio romântico, reprimido, por definição, pelos limites confinantes das instituições organizadas. Este padrão geral foi exacerbado no caso da França, que utilizava um sistema excessivamente centralizado. ${ }^{11}$ De acordo com as categorias analíticas desenvolvidas por Howard Becker, que se aplicam particularmente ao caso francês, os 
artistas se classificam em dois tipos: profissionais certificados e integrados ou dissidentes rejeitados. ${ }^{12}$ Neste sentido, os dissidentes são vistos - e muitas vezes assim se apresentam - como alienados aos valores artísticos tradicionais ou oficiais de seu tempo, os quais consideram violar claramente o status de quase-sacerdócio que atribuem à arte e à posição deles próprios em relação a ela.

Os prejuízos sofridos pelos artistas excluídos ao optarem por rejeitar os cânones da academia, ou simplesmente por não se relacionarem com o grupo certo de acadêmicos poderosos, foram tanto simbólicos quanto econômicos. Para os artistas financeiramente independentes, tais como Manet, a rejeição pode ter sido mais fácil de suportar do que no caso daqueles com recursos mais modestos. Muito poucos foram ameaçados de sofrer graves consequências simplesmente por conta de suas inovações estilísticas. Meio século mais tarde, nos estados totalitários da Alemanha nazista e da União Soviética, ser dissidente tornou-se muito mais perigoso. Em particular, a relação entre a arte moderna e a arte dos grupos reprovados, como os insanos, os "primitivos", os inválidos e aqueles definidos como alheios à linhagem pura nacional, como os judeus, foi utilizada para reforçar a rejeição a todas estas classes de criadores. Em seus ataques à arte Expressionista que viera a dominar a vanguarda da Alemanha e países vizinhos, os dogmatistas nazistas tratavam-na com o mesmo desdém que dispensavam à arte dos insanos. Em suas propagandas, ambas as formas artísticas eram tratadas como equivalentes. Ou seja, como símbolos da decadência cultural, um perigo à saúde da nação. ${ }^{13}$

Ao mesmo tempo, no entanto, o crescimento da arte outsider passou a convergir com as tendências da arte insider. Ao longo dos anos, ficou difícil categorizar as margens do mundo artístico. Tornou-se assustadoramente evidente que as barreiras entre alta arte e baixa arte, arte e política, arte e rito religioso, arte e expressão emocional, arte e a própria vida vêm sendo repetidamente borradas e ultrapassadas. Quando pilhas de tijolos são exibidas em museus, quando músicas são compostas para serem executadas embaixo d'água, as fronteiras entre os gêneros tornam-se tão fluidas que os velhos conceitos convencionais de arte tornam-se quase indiscerníveis. De fato, um dos resultados destes ataques à convenção - nos quais a valorização 
da periferia chegou a níveis jamais previstos - é que ficou praticamente impossível encontrar um centro do conceito de estética. Estes movimentos foram alvo de críticas, muitas vezes impulsionadas por conservadorismo politico, estético, ou mesmo ambos.

Da parte dos sociólogos, a natureza pluralista das artes já foi interpretada a partir de pontos de vista diferentes e, por vezes, conflitantes. Para Becker, trata-se de mundos artísticos da subcultura. Já os membros da Escola de Frankfurt, como Max Horkheimer e Theodor Adorno, os veem como implementos das indústrias de cultura comercial invadindo o espaço das belas artes. Pierre Bourdieu (1984) e Paul DiMaggio (1982), entre outros, consideraram-nos, pelo menos em parte, como pretextos para a exclusão de determinados grupos sociais, de forma a eliminar seu acesso ao status de elite cultural. Na percepção de Jeffrey Goldfarb (1989), são defesas erigidas pelos outsiders políticos, em uma tentativa de criar e manter uma esfera pessoal de liberdade frente ao totalitarismo. Apesar das diferenças em suas premissas básicas, abordagens e orientações políticas, todos estes analistas concordam que as artes e sua valorização são construções sociais, e não objetos fixos e incontroversos. ${ }^{14}$

\section{Outsiders contemporâneos - o surgimento de um campo}

Ao examinar o surgimento desta categoria no contexto de sua aparição histórica, sugerimos que a arte outsider "marginal", frequentemente reprovada, deva ser considerada em relação às formas estabelecidas da arte insider "central". No entanto, o centro estabelecido das artes tem sido atacado pelas formas emergentes, seja por seus criadores ou seus defensores, há no mínimo dois séculos. Na análise da ideia de marginalidade, são levados em consideração os escritos dos historiadores e teóricos sociais. A arte outsider é definida em termos de uma tipologia que inclui a arte dos insanos (PRINZHORN); dos primitivos, ingênuos e crianças (RUBIN; GOLDWATER); dos grupos relegados às margens dos mundos artísticos estabelecidos, tais como mulheres, negros e pintores antiacadêmicos (WHITE E WHITE, 1965; WOLFF, 2003); e dos intelectuais

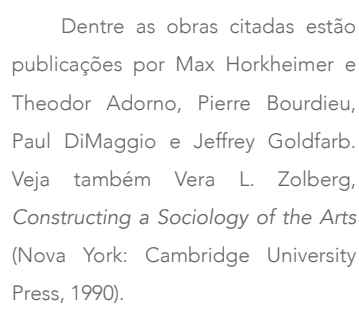


literários aspirantes (GRAÑA, 1964). Isto nos leva à questão da validade da dicotomia conceitual entre outsider e insider, especialmente nas condições associadas ao pós-modernismo, onde a ideia de centro pode já estar diluída a ponto de ser erradicada. Será que a própria mudança é hoje o centro? Seria proveitoso aplicar a ótica de um Darwinismo estético que leva à sobrevivência ou à extinção?

O que leva determinados objetos a receberem o status de "arte", enquanto outros são qualificados de diversas outras formas, como "históricos", "etnográficos", "entretenimento"? Quais são as condições que levam determinadas obras a serem integradas ao "cânone" enquanto seus próprios criadores são excluídos? De que forma o cânone poderá ser sobrepujado por novos outsiders e seus respectivos gêneros? Quanto aos públicos-alvo, de que forma são subdivididos pelos empreendedores e pelas instituições da arte, de acordo com a arte "oferecida" a eles? De que forma os criadores manipulam as estruturas culturais em nome de suas próprias carreiras, e quais são as consequências disso? As respostas a questões como estas contribuirão para uma análise das relações entre as condições macrossociais, as agências intermediárias e as instituições da cultura, bem como o papel do agente humano individual nos mundos da arte e a importância das considerações estéticas. É preciso continuar a análise destes processos e temas, dadas suas implicações para o mundo moderno e pós-moderno.

Recebido em 08/12/2016 